\title{
Multidisciplinary teaching in a formal medical ethics course for clinical students
}

\author{
W G Irwin, R J McClelland, R W Stout, M Stchedroff The Queen's University of Belfast
}

\section{Introduction}

There is now an impressive literature on the study and teaching of medical ethics and its teaching has expanded nationally and internationally. In 1980 the General Medical Council's recommendations (1) decreed that the subject should be taught to all medical students. The recent publication of the Report of a Working Party on the Teaching of Medical Ethics, The Pond Report (2), has provided a fresh stimulus in this area to medical students. The relevance of medical ethics to practice should be obvious to all doctors. Moral philosophy is concerned with the critical study of morality and it cannot exist in a vacuum but 'must examine real life problems, and, in this context, be used to assist doctors both to be effective clinically and to take correct moral options' (3).

A successful feature of the 4th-year curriculum in the Medical Faculty of the Queen's University, Belfast has been the development of interdisciplinary teaching in a three-week joint course to which several clinical departments contribute (4). Even before The Pond Report was published, the co-authors of this paper had judged the time and climate were right to plan formal multidisciplinary medical ethics teaching in the Belfast curriculum. We had already considerable experience of integrated teaching and the ready availability of interested clinical teachers willing to learn more about the topic. Co-ordinated teaching of topics of common interest in small groups included, until the academic year 1987/88, a three-hour session on medical ethics. In the Spring of 1987 the authors approached the Department of Philosophy at Queen's; subsequently proposals for a formal multidisciplinary course in medical ethics for 4th-year clinical students in the Medical Faculty, for the academic year 1987/88, were approved by the Education Committee of the Medical Faculty.

Specific learning objectives, content, teaching and methods of assessment were subsequently considered and agreed. Didactic styles of instruction in the course were to be kept to a minimum. Basic factual knowledge

\section{Key words}

Medical ethics teaching. of ethical principles, doctrines and codes was to be made available in handouts and short introductory talks, and also in the 4th-year student handbook in general practice.

\section{Learning objectives: rationale}

We took as our rationale the following, using $\mathbf{R} A$ Wright. Human Values in Health Care, (5):

1. Medical students bring personal sets of moral values;

2. These values are probably fixed without critical thought;

3. The philosophical perspective develops reflective cognitive skills relevant to decision-making in medicine and helps students:

3.1. to identify underlying ethical problems;

3.2. to identify and analyse available options;

3.3. to select one of the alternatives;

3.4. to justify that selection;

3.5. to learn that there is not always an 'absolute answer' to each moral question.

In due course the Education Committee of the Faculty of Medicine agreed the following learning objectives for the proposed new ethics course:

1. To help the student to analyse competently a clinical situation or problem;

2. To help the student to identify moral issues inherent in clinical situations;

3. To introduce a range of moral concepts, principles and codes used frequently in the discussions of medical ethics and to relate them to everyday morality;

4. To encourage the student to examine his or her own values, beliefs and attitudes and to relate to those of others;

5. To encourage the student to give his own views, based on reasoned moral argument, on moral issues related to practice.

\section{Teaching arrangements}

The need for co-ordinators from both the Faculty of Medicine and the Department of Philosophy soon became evident. WGI and MS assumed these 
respective roles. Five teams, comprising clinicians from a wide range of clinical specialties and philosophers, were formed who were willing:

1. To maintain continuity of teaching and content;

2. To learn further about the subject;

3. To meet with each other before each teaching session to clarify clinical and ethical details of the case studies to be discussed with the students.

\section{The 4th-year medical ethics course}

The departments of General Practice, Geriatric Medicine and Mental Health form the bedrock of integrated teaching in the 4th-year curriculum in Belfast. Medical ethics teaching was developed within the existing joint course in which one third of the year's intake (ie 50 students) takes part. This programme is repeated three times each year with the first group of students participating in September, the second in December and the third in March. Each programme consists of five sessions, each of three hours in duration. There are four afternoon sessions in one week followed by a morning session the following week. A team of six philosophers co-ordinated by MS joins with some 27 clinicians from most medical specialties and the course is held in the Department of General Practice.

Two key teaching strategies have been the involvement of a broad spectrum of clinical departments and joint teaching with the Department of Philosophy. (Topical questions of interest to medical students in many specialties make it necessary that the course develops along the lines of specialty interests in medicine). As well as contributions from General Practice, Geriatric Medicine and Mental Health, doctors from the Departments of Medicine, Surgery, Obstetrics, Child Health, Anaesthetics and Oncology also take part. The medical authors have been very impressed by the enthusiasm and dedication of the team of philosophers, four of whom are from the University Department of Philosophy, one from the Department of Jurisprudence in the University Law Faculty, and one from the Department of Health and Social Services, N Ireland. They attend each session, thus providing continuity of teaching and meet regularly with the respective clinicians before each teaching module to discuss the content of work to be presented.

\section{Teaching format}

Each of the teaching sessions consists of an introductory forum for an hour with fifty students, followed by a coffee break, and then an hour and a half in four discussion groups with a philosopher and one or more clinicians. Table 1 shows the teaching programme, the topics covered and the departments involved in each session. This is repeated three times in the year.

The first session is opened by WGI who introduce the students to the panel of experts (philosophers an clinicians) and over a 15-20 minute period defines the learning objectives, general ethical principles,

\section{Table 1}

\begin{tabular}{|c|c|c|}
\hline Session & Departments & Topics \\
\hline 1 & $\begin{array}{l}\text { General Practice/Geriatric } \\
\text { Medicine/Philosophy }\end{array}$ & $\begin{array}{l}\text { Autonomy, consent, telling } \\
\text { the truth, confidentiality, } \\
\text { allocation of resources, } \\
\text { limitation of treatment }\end{array}$ \\
\hline 2 & Surgery/Philosophy & $\begin{array}{l}\text { Autonomy, consent, } \\
\text { resuscitation, euthanasia, } \\
\text { defining death }\end{array}$ \\
\hline 3 & Child Health/Philosophy & $\begin{array}{l}\text { Autonomy of the child, } \\
\text { management of the } \\
\text { handicapped, } \\
\text { child abuse, research ethics }\end{array}$ \\
\hline 4 & $\begin{array}{l}\text { Obstetrics \& Gynaecology/ } \\
\text { Philosophy }\end{array}$ & $\begin{array}{l}\text { Prenatal fetal diagnosis, } \\
\text { abortion, euthanasia, } \\
\text { sterilisation, IVF, } \\
\text { embryo production, ovum, } \\
\text { donation, NHS limited resources }\end{array}$ \\
\hline 5 & Mental Health/Philosophy & $\begin{array}{l}\text { Impaired autonomy, } \\
\text { paternalism, confidentiality, } \\
\text { resource allocation, } \\
\text { research ethics }\end{array}$ \\
\hline
\end{tabular}


doctrines and codes. Following this and at all subsequent seminars there is general discussion led by one of the philosophers. A clinician then introduces the first case study of the day. After a coffee break the students form four small groups for further discussion of cases, each group has an attached philosopher and at least one medical teacher. The topics and cases have all been thoroughly discussed one week beforehand by clinicians from the relevant medical specialty and the six philosophers. A nominated clinician liaises with the link-philosopher to set up the meeting and is responsible for the running of the teaching session to follow and for the cases to be submitted for discussion.

\section{Methods of assessment of learning}

We are conscious that The Pond Report recommended that 'examination questions or essays on ethical issues should be included in the assessment leading to a medical qualification' and we intend to develop such an assessment in due course. As we have just completed the second of the three medical ethical courses to be provided for 4th-year students in 1987/88 we feel it important to eliminate first any teething problems before testing student learning.

\section{Value-effectiveness of the seminars}

There were such 'teething problems' when the new course was launched in September 1987, the significance of which depended upon one's perspective. From the doctor's viewpoint these could be summarised as:

1. Occasionally philosophers had overestimated the motivation and intellectual background of both students and doctors to understand ethical reasoning, which was often, because of perceived time constraints, argued at very high speed, especially in the introductory session. The need to keep the matter as simple as possible soon became evident.

2. Students complained of the inevitable repetition of topics over different specialties and a lack of coordination of content, which led to some confusion.

3. A few of the initial group of medical teachers were uncertain about their role, the format of teaching and the administrative arrangements. This caused a degree of disillusionment amongst some students and philosophers.

4. Some of the case histories submitted were too complicated in clinical terms and the ethical issues were not adequately defined. This was not as the philosophers would have wished either.

From the perspective of the philosophers the difficulties were:

1. Case histories should have been distributed earlier so that clinical and ethical issues could have been defined beforehand and learning built around the moral issues arising.
2. Students needed to understand better how moral theory and practice come together in decision-making in medicine.

3. Too many moral issues were debated at the one time and problems were therefore not dealt with in suitable depth.

4. Students were technically inept at appraising critically opposing moral points of view.

5. Case histories were too complicated with overemphasis on 'clinical details' leading to 'medical dominance'.

6. The students had an inadequate foundation of general ethical theory and failed to grasp adequately the presentation of ethical ideas.

Following the first series of seminars the clinicians, coordinators and philosophers met to discuss these difficulties and to devise improvements for the December 1987 course. Attention was paid to the following aspects of preparation and format:

1. Case histories were made simpler, pruned of unnecessary clinical data, distributed earlier and the philosophers met the relevant doctors in each speciality at least one week before the teaching session was due. 2. The philosophers agreed to 'simplify' and shorten their introductory presentations.

3. Topics were clearly defined for each session if relation to the case studies submitted and repetitio was used only when reinforcement was considered be both practical and educationally desirable.

4. During the opening forum the roles of the clinicians and the philosophers were more clearly defined with a short introduction by both before general discussion took place. The clinician introduced the case study and the philosopher commented on the ethical issues.

5. It was agreed to attempt to explore as many topics as possible, in suitable depth, in the time available.

As a consequence of adopting these measures the second cycle was considerably enhanced, as judged by both teachers and student opinion.

\section{Student evaluation of the course}

Students were asked their opinion of various aspects of the course, for example, the length of each session, the number of sessions, the quality of teaching, the content of learning, the format, integrated teaching with philosophers, etc and marked a 1-5 evaluation scale $N$ $(1=$ very good and $5=$ bad $)$ at the end of the course. $\underset{\omega}{N}$ On the whole the course was regarded as very successful for both staff and students. Some were 0 hostile to philosophy, but most found the classes a very positive experience. A majority criticised the open $\stackrel{\odot}{\rightarrow}$ forum and would have wished to divide into small 0 groups earlier.

Surprisingly the following received no adverse criticism: the length of sessions or course; the number of sessions; the quality and content of learning. Not surprisingly the use of clinical examples and small- 
group learning were highly praised. Large groups apparently confused the students about the issues under debate and many did not participate in discussion; the overall desire appeared to be for smallgroup teaching.

It was encouraging to see the qualitative change in the current course compared with the last cycle, our first experience. Clearly there are still improvements to be considered and implemented before the next module, particularly with respect to both the discussion of case material and the case materials themselves and the presentation of ethical ideas and theory, but the programme of development is gaining impetus from the increasing enthusiasm and motivation of all taking part in the course.

\section{Acknowledgements}

We thank all the clinicians and the team of philosophers - Marcel Stchedroff, Max Wright, Christopher McKnight, Laura Arthurs, Peter Ingram and Stephen Peover for their willing co-operation during this study. Our thanks are due also to Professor David Evans, Head of the Department of Philosophy, the Queen's University, Belfast for his support in developing the course.
W G Irwin MD FRCGP is Professor of General Practice, $R \mathcal{F}$ McClelland MD PhD FRCPsych is Professor of Mental Health, $R W$ Stout MD FRCP is Professor of Geriatric Medicine and $M$ Stchedroff BAMA is Lecturer in Philosophy, all at The Queen's University of Belfast. Correspondence to: Professor W G Irwin, Department of General Practice, The Queen's University of Belfast, Dunluce Health Centre, 1 Dunluce Avenue, Belfast BT9 7HR.

\section{References}

(1) General Medical Council, Education Committee. Recommendations on basic medical education. Rochester: Stanhope Press, 1980.

(2) Institute of Medical Ethics. Report of a working party on the teaching of medical ethics. Chairman: Sir Desmond Pond. London: I M E Publications Ltd, 1987.

(3) Irwin W G. Medical ethics. Presidential address given to the Ulster Medical Society 1986, Oct 30. The Ulster medical journal 1987; 56, 1: 1-12.

(4) Stout R W, Irwin W G. Integrated medical student teaching. A combined course in community medicine, general practice, geriatric medicine and mental health. Medical education 1982; 16: 143-146.

(5) Wright R A. Human values in health care: the practice of ethics. USA: McGraw-Hill, 1987. 